\section{Intestinal Microbial Diversity and Perioperative Complications}

\author{
Matthew W. Ralls, MD; Eiichi Miyasaka, MD; and Daniel H. Teitelbaum, MD
}

Journal of Parenteral and Enteral

Nutrition

Volume 38 Number 3

March 2014 392-399

(C) 2013 American Society

for Parenteral and Enteral Nutrition

DOI: $10.1177 / 0148607113486482$

jpen.sagepub.com

hosted at

online.sagepub.com

(\$SAGE

\begin{abstract}
Background and Aims: Enteral nutrient deprivation via parenteral nutrition (PN) in a mouse model leads to a local mucosal inflammatory response. This proinflammatory response leads to a loss of epithelial barrier function and atrophy of the intestine. Although the underlying mechanisms are unknown, a potential contributing factor is the impact PN has on the intestinal microbiome. We recently identified a shift in the intestinal microbial community in mice given PN; however, it is unknown whether such changes occur in humans. We hypothesized that similar microbial changes occur in humans during periods of enteral nutrient deprivation. Methods: A series of small bowel specimens were obtained from pediatric and adult patients undergoing small intestinal resection. Mucosally associated bacteria were harvested and analyzed using 454 pyrosequencing techniques. Statistical analysis of microbial diversity and differences in microbial characteristics were assessed between enterally fed and enterally deprived portions of the intestine. Occurrence of postoperative infectious and anastomotic complications was also examined. Results: Pyrosequencing demonstrated a wide variability in microbial diversity within all groups. Principal coordinate analysis demonstrated only a partial stratification of microbial communities between fed and enterally deprived groups. Interestingly, a tight correlation was identified in patients who had a low level of enteric microbial diversity and those who developed postoperative enteric-derived infections or intestinal anastomotic disruption. Conclusions: Loss of enteral nutrients and systemic antibiotic therapy in humans is associated with a significant loss of microbial biodiversity within the small bowel mucosa. These changes were associated with a number of enteric-derived intestinal infections and intestinal anastomotic disruptions. (JPEN J Parenter Enteral Nutr. 2014;38:392-399)
\end{abstract}

\title{
Keywords
}

intestine; microbiota; microflora; parenteral nutrition

\section{Clinical Relevancy Statement}

Parenteral nutrition (PN) is widely used in the pediatric and adult population for patients with short- and long-term intestinal failure. The benefits of this therapy are clear, but there are many detrimental effects associated with its use. There is little understanding of the underlying mechanisms for many of the known complications described with PN. This study represents the first report to investigate the intestinal microbiome in those patients on PN. Regardless of cause, low intestinal microbial diversity correlates with increased incidence of anastomotic and infectious complications. An improved understanding of the interaction between loss of enteral nutrition, the microbiome, and the host response may lead to therapy to decrease complications in an already high-risk population.

\section{Introduction}

Parenteral nutrition (PN) is an alternative form of nutrition for those patients with short-term gastrointestinal (GI) dysfunction, ${ }^{1}$ as well as a life-saving nutrition replacement for patients with intestinal failure requiring long-term support. ${ }^{2,3}$ Although essential and clearly beneficial for many, PN use is associated with numerous complications ranging from an increase in systemic infections to a loss of immune reactivity. ${ }^{4-8}$ Previous studies have shown distinct physical and immunologic differences in the intestinal immunology of mice maintained on PN. ${ }^{9-15}$ These changes include increased inflammatory cytokines and decreased regulatory cytokines within the bowel

From the Section of Pediatric Surgery, Department of Surgery, University of Michigan, Ann Arbor, Michigan.

Matthew W. Ralls and Eiichi Miyasaka contributed equally to this work.

Financial disclosure: T-32HD007505 (to E.M.) and NIH-R01 AI-4407614 (to D.H.T.)

Received for publication November 7, 2012; accepted for publication March 22, 2013.

This article originally appeared online on May 1, 2013.

Corresponding Author:

Daniel H. Teitelbaum, MD, Section of Pediatric Surgery, University of Michigan, Mott Children's Hospital, 1540 E. Hospital Dr, SPC 4211, Ann Arbor, MI 48109-4211, USA.

Email:dttlbm@umich.edu

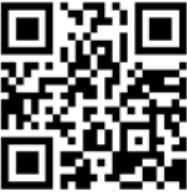

Download a QR code reader on your smartphone, scan this image, and listen to the podcast for this article instantly. Or listen to this and other JPEN podcasts at http://online library.wiley.com/journal/10.1002 (ISSN) 1941-2444/homepage/podcasts.htm. 
wall, leading to a proinflammatory state in the GI tract. There is also a decrease in intestinal epithelial cell proliferation and an increase in apoptosis with an associated atrophy of the small bowel mucosa. ${ }^{16-18}$ The underlying mechanisms for the above changes are unknown, but the immunologic disorder may lead to a loss of epithelial barrier function $(\mathrm{EBF})^{18,19}$ and is theorized to increase bacterial translocation through a more permeable intestinal mucosa. ${ }^{20-22}$

Enteral deprivation may help explain the dramatic observations seen in our PN mouse model. PN provides sufficient energy and nutrient needs but puts the intestinal microbiota in an abrupt state of nutrient withdrawal. The intestinal microbial population is highly sensitive to local environmental alterations and may rapidly change its composition in response to such dramatic nutrition deviation from baseline. ${ }^{23,24}$ In mice, administration of PN leads to profound changes in the small intestinal microbiota, moving from a Gram-positive Firmicutes flora to a Gram-negative Proteobacteria-dominated community. $^{25}$

Although the above-mentioned small bowel and microbial changes are well documented in rodent models of PN administration, it is less clear whether such changes occur in humans. ${ }^{26-30}$ A major limitation of previous studies is that each is based on very limited numbers of patients, and only a very superficial evaluation of mucosal changes has been investigated. Importantly, no previous study has investigated whether the administration of $\mathrm{PN}$ results in changes in the microbial population of the GI tract. Alteration in types of nutrient feeding has long been thought to affect the composition of the human intestinal microbiome. ${ }^{31}$ Such fluctuations have been implicated in the development of a number of pathologic conditions, including necrotizing enterocolitis, inflammatory bowel disease, ${ }^{32}$ obesity, ${ }^{33}$ and food allergies. ${ }^{34}$ A deep understanding of the microbial shifts associated with each disease process has been difficult in humans as each person has a unique microbiome, making concrete correlations challenging. ${ }^{35}$ Whether the complete removal of enteral nutrition (EN) from a portion of the intestine affects the composition of the microbial population has yet to be tested in humans, yet this extreme modification in nutrient delivery has the potential to best address the implications of nutrients on the alteration of the intestinal microbial communities. To address this, we used a series of surgical biopsy specimens from the small bowel of patients and compared the microbiota with relation to the degree of enteral nutrient deprivation. Secondarily, we followed the clinical course of each patient from whom a sample was taken.

\section{Methods}

\section{Handling of Human Tissue}

All experiments were done in accordance with the University of Michigan Institutional Review Board (HUM00024263). In all cases, the degree to which the small bowel segment was in contact with enteral nutrients was recorded. All specimens were sent fresh to pathology from the operating room. Adhering to sterile technique, a pathologist performed gross examination of the specimen. A fresh portion of the specimen was cut and placed into sterile RPMI 1640 with glutamine (Invitrogen, Carlsbad, CA) and taken to the laboratory for tissue processing (see later paragraphs). All samples were de-identified; however, the following data were recorded: patient age, diagnosis, sex, location of bowel, whether the bowel was exposed to enteral nutrients or not, and duration of enteral nutrient deprivation. Definition of enteral nutrient deprivation included the following: isolated intestinal segments or defunctionalized limbs of bowel, without exposure to enteral nutrients. In addition, nutrient deprivation included patients without any enteral nutrients. Patients with active inflammatory conditions (eg, Crohn's disease, active necrotizing enterocolitis) were excluded.

\section{Bacterial Pyrosequencing}

From each segment, tissue was opened, with adherent stool rinsed off in sterile media consisting of RPMI 1640 with glutamine (Invitrogen) and 5\% fetal bovine serum (FBS; Invitrogen). The tissue was then scraped to obtain the mucosally associated bacteria and snap-frozen in liquid nitrogen until analyzed. The bacterial tag-encoded FLX-Titanium amplicon pyrosequencing method targeting the V1-V3 variable regions of $16 \mathrm{~S}$ rRNA was used to create amplicon libraries. ${ }^{36} \mathrm{~V} 1-\mathrm{V} 3$ primer sets corresponded to $27 \mathrm{~F}$ (5'-GAGTTTGATCNTGGCTCAG-3') and 519R (5'-GTNTTACNGCGGCKGCTG-3'), along with appropriate sample nucleotide barcodes and the Roche (Basel, Switzerland) A\&B primers. Pyrosequencing was performed following established protocols ${ }^{37}$ at Research and Testing Laboratories (Lubbock, TX).

Identified sequences were then classified using the Michigan State Ribosomal Database Project (RDP) classifier. Analysis of sequenced data was performed using Mothur, an open-source, community-supported software for describing and comparing microbial communities,${ }^{38}$ following the example of Costello Stool Analysis with default software settings. The metrics we examined were $\alpha$ and $\beta$-diversity Unifrac principal coordinate analyses.

Another metric to evaluate the microbiota is the inverse Simpson index, which is an example of an $\alpha$-diversity measure that describes how much variety exists within a given community. The Simpson index always falls between 0 and 1 , with 0 meaning infinite variety and 1 meaning no variety. The inverse Simpson index is more intuitive in that higher numbers indicate higher $\alpha$-diversity (or variety, and thus the greater the score, the higher the diversity).

\section{Statistical Analysis}

We used $\alpha$-diversity and Unifrac principal coordinate analysis to study the microbial communities. The inverse Simpson 
Table 1. Patient Demographics and Clinical Information of Patients From Which Small Bowel Was Collected and Studied.

\begin{tabular}{|c|c|c|c|c|c|c|}
\hline ID, Sex/Age & Additional History & Feed Status & $\begin{array}{l}\text { Antibiotics: (Other } \\
\text { Than Preoperative) }\end{array}$ & $\begin{array}{l}\text { Immune } \\
\text { Modulator }\end{array}$ & Prior Infections & Complication \\
\hline $\begin{array}{l}\text { Newborn1* } \\
\text { F/2 d }\end{array}$ & Ileal atresia & NPO & & & & \\
\hline $\begin{array}{l}\text { Newborn2* } \\
\text { F/2 d }\end{array}$ & Ileal atresia & NPO & & & & \\
\hline $\begin{array}{l}\text { Chronic } \\
\text { NPO } \\
\text { F/16 y }\end{array}$ & IBD & $\mathrm{NPO} \times 2 \mathrm{mo}, \mathrm{PN}$ & $\begin{array}{l}\text { Amox/ } \\
\text { clavulanate and } \\
\text { metronidazole } \\
(\mathrm{H})\end{array}$ & & $\begin{array}{l}\alpha \text { Strep, line } \\
\text { infection }\end{array}$ & $\begin{array}{l}\text { EC fistula from } \\
\text { anastomosis }\end{array}$ \\
\hline $\begin{array}{l}\text { MF1 } \\
\text { M/3 mo }\end{array}$ & Previous NEC & MF not fed & Gentamicin $(\mathrm{P})$ & & Klebsiella UTI & \\
\hline $\begin{array}{l}\text { MF2 }^{\dagger} \\
\text { M/17 y }\end{array}$ & Previous blunt trauma & MF not fed & & & & \\
\hline $\begin{array}{l}\text { Partial1 } \\
\mathrm{M} / 3 \mathrm{mo}\end{array}$ & Previous NEC & $\mathrm{PN}$ and feeds & Gentamicin $(\mathrm{P})$ & & Klebsiella UTI & \\
\hline $\begin{array}{l}\text { Partial2 } \\
\mathrm{M} / 2 \mathrm{mo}\end{array}$ & Previous NEC & $\mathrm{PN}$ and feeds & Pip/Tazo (P) & & $\begin{array}{l}\text { Klebsiella } \\
\text { bacteremia }\end{array}$ & $\begin{array}{l}\text { Central venous } \\
\text { line infection } \\
(\text { Klebsiella })\end{array}$ \\
\hline $\begin{array}{l}\text { Partial3 } \\
\mathrm{F} / 22 \mathrm{y}\end{array}$ & $\begin{array}{l}\text { Cloacal exstrophy, } \\
\text { parastomal hernia }\end{array}$ & $\mathrm{PN}$ and feeds & $\begin{array}{l}\text { Metronidazole, } \\
\text { nystatin, } \\
\text { aztreonam (A) }\end{array}$ & & $\begin{array}{l}\text { Escherichia coli } \\
\text { UTI }\end{array}$ & \\
\hline $\begin{array}{l}\text { Full feeds1 } \\
\text { F/3 y }\end{array}$ & $\begin{array}{l}\text { History of malrotation, } \\
\text { jejunal stricture }\end{array}$ & $\begin{array}{l}\text { Full feeds, clear } \\
\text { liquid diet } 5 \\
\text { days }\end{array}$ & & & & $\begin{array}{l}\text { Anastomotic ulcer } \\
\text { and stricture }\end{array}$ \\
\hline $\begin{array}{l}\text { Full feeds } 2^{\dagger} \\
\mathrm{M} / 17 \mathrm{y}\end{array}$ & Previous blunt trauma & Full feeds & & & & \\
\hline $\begin{array}{l}\text { Full feeds3 } \\
M / 17 \mathrm{y}\end{array}$ & IBD & Full feeds & & Steroids $(\mathrm{H})$ & & $\begin{array}{l}\text { Wound infection } \\
\text { (MSSA) }\end{array}$ \\
\hline $\begin{array}{l}\text { Full feeds4 } \\
\mathrm{M} / 8 \mathrm{mo}\end{array}$ & Hirschsprung disease & Full feeds & $\begin{array}{l}\text { Multiple antibiotics } \\
\text { regimen }(\mathrm{P})\end{array}$ & & & $\begin{array}{l}\text { Recurrent } \\
\text { enterocolitis }\end{array}$ \\
\hline $\begin{array}{l}\text { Full feeds5 } \\
M / 22 y\end{array}$ & $\begin{array}{l}\text { IBD with small bowel } \\
\text { obstruction }\end{array}$ & Full Feeds & $\begin{array}{l}\text { Pip/Tazo and } \\
\text { metronidazole }(\mathrm{P})\end{array}$ & Steroids (A) & Unclear etiology & $\begin{array}{l}\text { Wound infection } \\
\text { (Klebsiella, } \\
\text { Candida })\end{array}$ \\
\hline $\begin{array}{l}\text { Full feeds6 } \\
\text { F/9 y }\end{array}$ & $\begin{array}{l}\text { EC fistula following } \\
\text { jejunal tube }\end{array}$ & Full feeds & & & & \\
\hline $\begin{array}{l}\text { Full feeds7 } \\
\text { F/7 y }\end{array}$ & Previous NEC & Full feeds & Pip/Tazo (P) & & $\begin{array}{l}\text { Enterococcus, } \\
\text { Pseudomonas }\end{array}$ & Anastomotic leak \\
\hline
\end{tabular}

$*+$ denote samples from the same patient. A, active (denotes current therapy); Amox, amoxicillin; EC, enterocutaneous; H, historic (refers to prior treatment that ended 2 weeks or more before operation); IBD, inflammatory bowel disease; ID, identifier; MF, mucus fistula; MSSA, methicillinsensitive Staphylococcus aureus; NEC, necrotizing enterocolitis; NPO, nil per os; P, previous (refers to therapy continuing up to within 1 week of operation); Pip/Tazo, piperacillin and tazobactam; PN, parenteral nutrition; UTI, urinary tract infection.

index was further used to define the variability in diversity depending on degree of enteral nutrient deprivation. An arbitrary setting of 10 for the inverse Simpson index was used to stratify between low $(<10)$ and high $(\geq 10)$ diversity.

\section{Results}

\section{Demographics}

Fifteen samples from 12 different patients were collected for analysis of their microbiota between January 2009 and October 2010 (Table 1). Loop enterostomy takedown resulted in more samples than the number of patients. In these cases, $1 \mathrm{limb}$ of bowel had exposure to nutrients, and the other was isolated from nutrition (ie, in these cases, there was no refeeding of the distal limb). There were 6 males and 6 females with a mean \pm SD age of $9.2 \pm 8.4$ years (range, 2 days to 22 years). Additional items recorded included the disease process and location of the bowel. Intestinal samples were ileal $(n=13)$ or jejunal $(n=2)$. The operative indications for resection were most commonly enterostomy takedown $(n=6)$. Others indications included enterocutaneous (EC) fistula takedown $(n=2)$, small bowel obstruction ( $\mathrm{n}=2$, from adhesive disease and anastomotic stricture), and 1 case each for ileal atresia and parastomal hernia. Underlying pathology included previous cases of necrotizing enterocolitis $(n=3)$, previous diagnosis of ulcerative colitis $(n=3)$, intestinal atresia, anastomotic stricture, cloacal 


\section{Phylum-level Pyrosequencing}

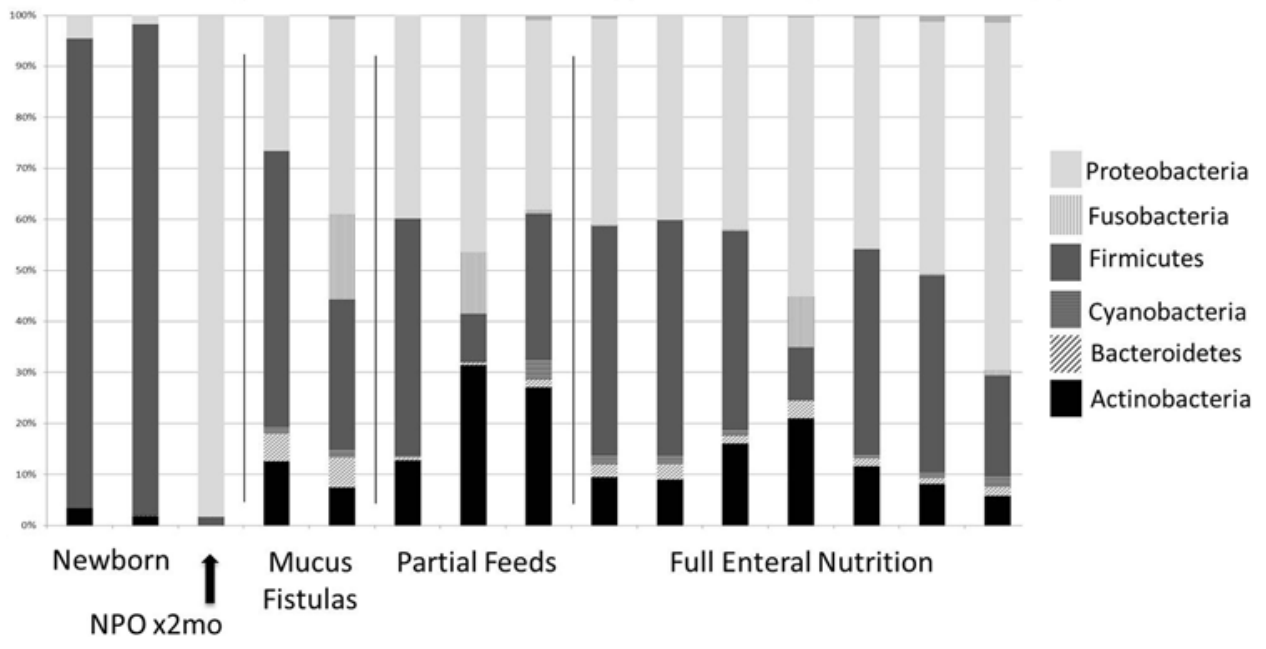

Figure 1. Phylum level analysis after Ribosomal Database Project (RDP) classification of pyrosequenced small bowel mucosaassociated bacteria samples. Groups of patients are broken down by degree of enteral nutrition, as well as by separating the 2 neonatal samples. Mucous fistula denotes bowel completely unexposed to nutrients, and partial feeding meant intestine where $<20 \%$ of nutrients entered the gastrointestinal tract. NPO, nil per os.

exstrophy, total colonic Hirschsprung disease, EC fistula, and trauma.

Seven samples were from fully fed segments of bowel and 3 were partially fed. The partially fed patients received the majority of nutrients parenterally $(>80 \%)$, as only trophic feedings were tolerated in these patients. All samples in the partially fed group were chronically (over 2 weeks) on PN support. Five samples were unfed, 3 of which had no EN for at least 6 weeks $(65,47$, and 42 days). Two of these came from patients with mucus fistulae out of continuity of enteric flow but receiving either full enteral feeds or partial feeds. The other patient was PN dependent with no EN for more than 2 months. Two samples were from neonates who never received enteral feedings.

\section{Pyrosequencing, Biodiversity, and Correlation to Clinical Outcomes}

Figure 1 shows the intestinal mirobiota sorted by phylum. Quite similar to most human data, there was marked heterogeneity among the samples. ${ }^{39}$ Three of these samples, however, stood out above all others. These were the 2 segments from the same 2-day-old infant and the sample from a patient who was without enteral nutrients for more than 2 months. These samples were distinct in that there was a marked loss of diversity in these patients who had little to no nutrient exposure. As it is known that neonatal fecal microbes are quite different from those in adults, ${ }^{40,41}$ the latter patient's microbiome (nil per os [NPO] for $>2$ months), which was composed virtually of all Proteobacteria, is more relevant to this study. The data suggest that prolonged periods of enteral deprivation can lead to a marked change in intestinal mucosal microbiota with a decline in its diversity.

A further breakdown of the bacterial genus is shown in Table 2. In the table, 3 representative nonfed and fed microbial populations are shown. Characteristic of human microbial populations, each patient had a unique distribution, but some important distinctions are found. Although there is a large overlap in speciation and no statistically significant differences found, some groups were expanded in the fed group (Staphylococcus, Pseudomonas, Campylobacter, Propionibacterium, Chryseomonas) and others in the enterally deprived group (Enterobacter, Shigella, Klebsiella, and Fusobacterium).

To better characterize and quantify differences in the intestinal flora between individuals, Unifrac principal coordinate analysis (PCoA) was applied to the samples. In PCoA, differences between microbial communities are first divided into multiple weighted components based on their genetic sequences or operational taxonomic units. Figure 2 shows the components that accounted for the largest percentage of the differences between communities and is expressed as an x-y plot. This unweighted PCoA plot of the first 2 axes accounted for $20.5 \%$ of the total differences between microbial communities in fed vs unfed bowel. In an unweighted analysis, only the presence or absence of a bacterium is counted. Because of this, the neonatal samples were distinctly different from the other samples. A clear separation of groups based on feeding status is not seen. There is a trend of unfed or partially fed samples clustering toward the bottom right and fully fed 
Table 2. Representative 454 Pyrosequencing Results at the Genus Level From 3 Nonfed (Excluding Neonatal Specimens) and 3 Enterally Fed Portions of Bowel.

\begin{tabular}{|c|c|c|c|c|c|c|}
\hline Bacterial Genus & NPO & NPO & NPO & Enteral & Enteral & Enteral \\
\hline Staphylococcus & 22 & 1274 & 523 & 962 & 1646 & 1597 \\
\hline Enterococcus & 33 & 1835 & 210 & 1385 & 57 & 199 \\
\hline Klebsiella & 11876 & 0 & 231 & 218 & 43 & 571 \\
\hline Pseudomonas & 1 & 466 & 538 & 1085 & 1351 & 1955 \\
\hline Shigella & 1475 & 43 & 186 & 210 & 82 & 197 \\
\hline Bifidobacterium & 0 & 0 & 37 & 0 & 54 & 12 \\
\hline Corynebacterium & 7 & 806 & 247 & 532 & 621 & 434 \\
\hline Campylobacter & 9 & 1 & 131 & 681 & 35 & 289 \\
\hline Fusobacterium & 1 & 1 & 1508 & 0 & 3 & 47 \\
\hline Enterobacter & 656 & 284 & 227 & 326 & 105 & 202 \\
\hline Anaerococcus & 6 & 263 & 88 & 259 & 152 & 211 \\
\hline Citrobacter & 456 & 1 & 282 & 56 & 21 & 447 \\
\hline Streptococcus & 2 & 199 & 334 & 167 & 285 & 215 \\
\hline Propionibacterium & 1 & 58 & 19 & 291 & 284 & 166 \\
\hline Proteus & 2 & 240 & 42 & 133 & 87 & 168 \\
\hline Finegoldia & 10 & 527 & 61 & 171 & 149 & 149 \\
\hline Clostridium & 68 & 0 & 45 & 69 & 2 & 96 \\
\hline Delftia & 0 & 0 & 198 & 1304 & 1 & 8 \\
\hline Prevotella & 0 & 384 & 322 & 248 & 55 & 25 \\
\hline Chryseomonas & 4 & 9 & 40 & 142 & 176 & 98 \\
\hline Allobaculum & 0 & 0 & 172 & 975 & 3 & 0 \\
\hline Veillonella & 13 & 113 & 68 & 0 & 38 & 18 \\
\hline Minor genera $(<1000)$ & 110 & 1178 & 2335 & 2455 & 1115 & 2226 \\
\hline Total called & 14,752 & 7682 & 7844 & 11,669 & 6365 & 9330 \\
\hline Total sequences & 16,921 & 8542 & 9137 & 13,773 & 7344 & 12,237 \\
\hline
\end{tabular}

Note the broader representation of bacteria from multiple bacterial genera. As well, note certain predominant Gram-negative groups in the nonfed patients, including Enterobacter, Shigella, Klebsiella, and Fusobacterium. NPO, nil per os.

samples clustering to the top left. This indicates an underlying similarity among the unfed vs fed intestinal samples. But, as with Table 2, there is no clear distinction of these groups based solely on feeding status.

To further analyze the microbiome data, we next performed an analysis of biodiversity. Figure 3 shows an analysis of the samples using inverse Simpson indices. At initial analyses, there appeared to be little correlation between $\alpha$-diversity and feeding status of the patients. However, a further analysis was performed examining those patients who had a postoperative infectious complication. Seven such postoperative complications were found, which included 3 anastomotic problems (2 with complete disruption), 2 abdominal wound infections (Klebsiella pneumoniae, Candida albicans in 1 patient and methicillin-sensitive Staphylococcus aureus [MSSA] in the other), 1 central venous line infection (K pneumoniae), and 1 case of recurrent enterocolitis.

Interestingly, the proportion of samples with a lower $\alpha$-diversity (or a lower inverse Simpson index, <10) was significantly ( $P<.01$ using $\chi^{2}$ analysis) greater (all but one patient) in the group of patients who had the above-listed postoperative complications, whereas those having a higher inverse
Simpson index fell into the group that was far less prone to infectious complications. In fact, no patient had infectious complications with an inverse Simpson index $>10$. This suggested that those patients with lower levels of biodiversity had an increased susceptibility to infections or potentially had a more virulent type of bacteria that predisposed them to these complications.

\section{Discussion}

Although the causality is not fully established, it was interesting that a significant increase in infectious and anastomotic complications was associated in those patients who had loss of microbial diversity. Such an increase in infectious complications has been well established in patients receiving $\mathrm{PN},{ }^{5,20,42}$ and the results suggest that lower diversity in the intestinal microbiome may affect these infectious complications. The lower diversity was not clearly defined in the fed and enterally deprived groups as hypothesized but rather seems multifactorial. Importantly, the 1 sample from which enteral nutrients was withheld for more than 2 months did have the lowest diversity. An in-depth investigation of 


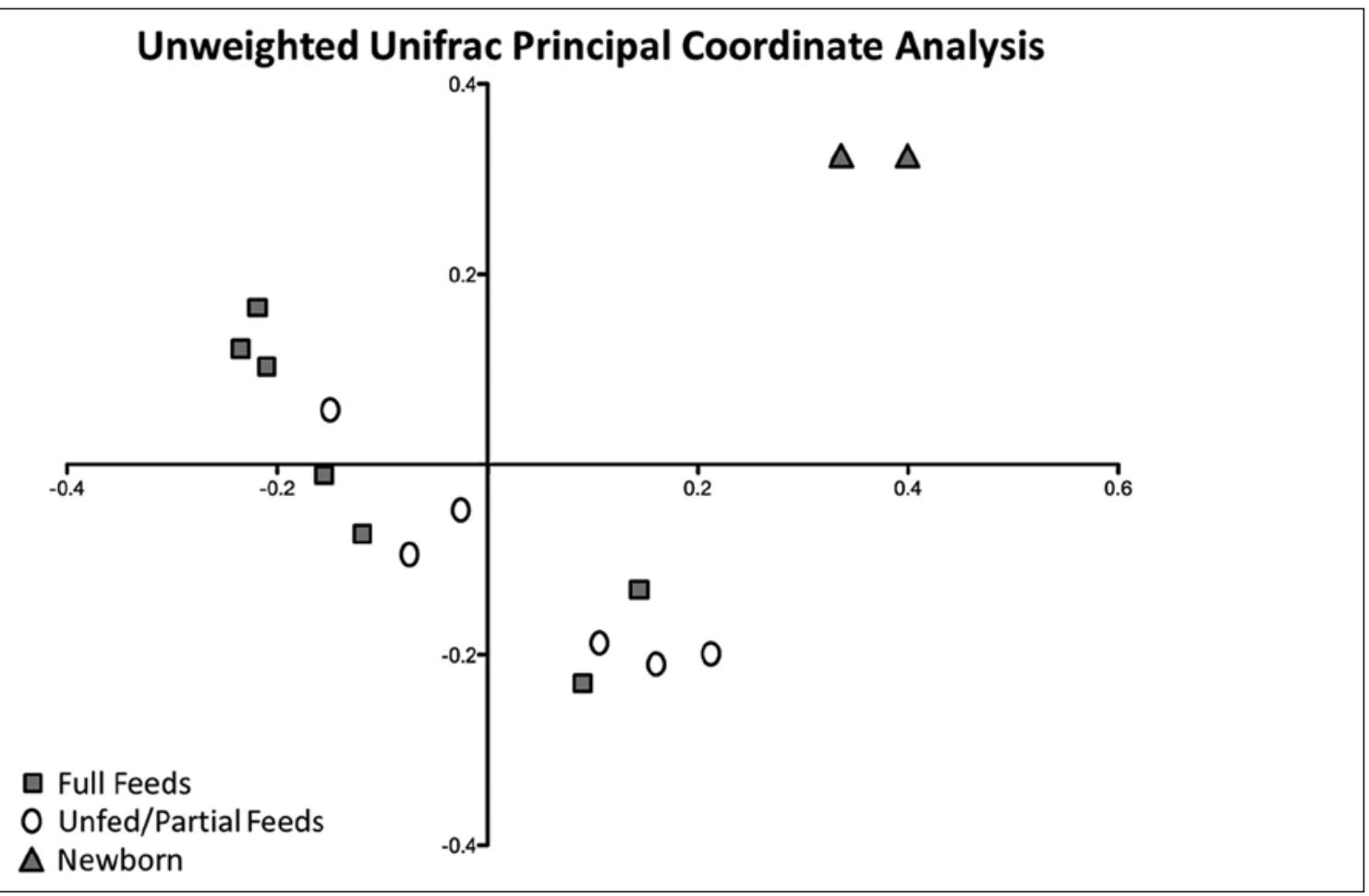

Figure 2. Unweighted Unifrac principal coordinate analysis of control and parenteral nutrition small bowel samples. Axis-1 (x) and axis-2 (y) account for $11.9 \%$ and $8.6 \%$ of overall differences, respectively.

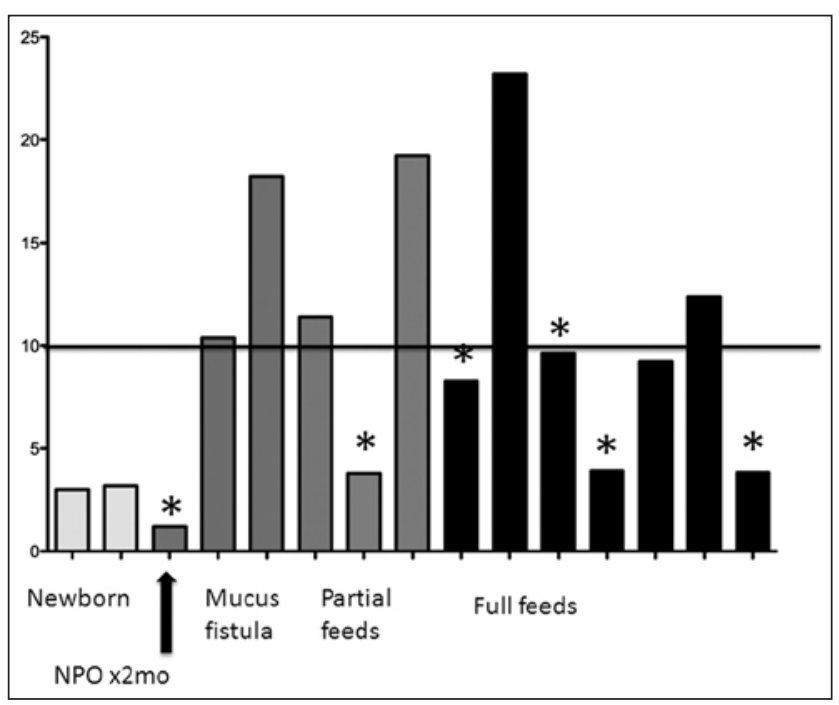

Figure 3. Inverse Simpson index and enteral nutrition. All patients outside of the newborn period with a sample that scored less than 10 , signifying a less diverse microbiota, were complicated with an infectious or anastomotic complication (*). NPO, nil per os.

more completely NPO individuals is needed to further substantiate this finding. It is also important to note that other confounding factors that could influence microbial diversity would include repetitive use of antimicrobial agents, as given in many of our patients in this study.
In both humans and rodents, the dominant intestinal phyla of bacteria are Firmicutes and Bacteroides, composed of mostly Gram-positive bacteria. ${ }^{43}$ Although the general trend of more Firmicutes and Bacteroides is present, the specific subphylum composition of the microbiota is quite variable. Thus, it was not surprising to see this overall diversity between the patients we examined. Our laboratory's mouse model of enteral nutrient deprivation with $\mathrm{PN}$ administration demonstrates a marked shift of the intestinal microbiota from that of a Firmicutes-dominant flora to that of a Proteobacteria-dominant population. Although there was a definite trend toward this shift in the human samples, a significant loss of diversity was not shown in all unfed portions of small intestine. However, this trend is best seen in the individual who was enterally deprived for 2 months and had a nearly complete shift to a Proteobacteria profile.

When specifically looking at the unfed samples, one could argue based on the RDP data (Figure 1) that 2 of the 5 unfed specimens are not dissimilar to the partially fed and fed samples. However, when considering the unfed specimens, it is critical to consider the patient history. The neonates, never having received food, had low diversity as expected. ${ }^{44}$ The third of the 5 patients who was totally NPO for 65 days showed a dramatic loss in microbial diversity. The other 2 samples were from mucus fistulae from patients with loop enterostomies. One may expect these samples to look more like the patient NPO for 65 days as these patients were out of intestinal continuity for a similar duration. Both of the patients with mucus 
fistulae were fed in their proximal limb. This is an important consideration as the bacterial contents from the proximal (fed limb) may have colonized the distal limb, resulting in greater diversity in this group. This could be the case as the stoma drains from the same stomal skin site into the same stool collection apparatus.

It was striking to note that the patients who developed infectious and anastomotic complications had a significantly lower microbial diversity using the inverse Simpson index regardless of feeding status. Other factors may influence the heterogeneity of microbes. One example could be patientspecific antimicrobial use that could disrupt the intestinal microflora. ${ }^{45}$ In this study, 4 of the 6 fed or partially fed patients who experienced a complication were on an antibiotic regimen at the time of the operation or recently completed antibiotic treatment prior to surgery (Table 1). There may be other contributing factors leading to loss of microbial diversity that were not uncovered in the current study, including exposures to other patients or pharmacologics that could influence the GI tract. Nevertheless, these data suggest a strong correlation between loss of microbial diversity and an aberration of underlying physiology of the bowel wall, leading to higher rates of infectious complications.

One of the limitations of this study is the relatively low sample numbers and a highly heterogeneous patient population. We also acknowledge that the cutoff of 10 for the inverse Simpson index is somewhat arbitrary, and further validation of this value is required to increase the robustness of this study. Furthermore, we have used pyrosequencing data to define the microbiota. Although a widely accepted method for analysis of the microbiome, currently there is little application of this technique in a clinical setting. These data provide a much more diverse set of microbes alluding to the presence of unculturable intestinal bacteria, yet clinically we must rely on culture data. Our analysis of the 454 data was also limited. Potentially, a much more complex examination could have been done. However, we believe that the data presented demonstrate the changes in microbial diversity and fit the needs of this study. Despite these limitations, we believe that our study provides valuable insight into the complex interaction between the host and its intestinal microbiota.

In conclusion, this study showed that a loss in microbial diversity is associated with an increase in postoperative microbial infections and other major GI surgical complications. It is possible that enteral nutrient deprivation, among other factors, leads to a shift in the microbiome and thus a loss of microbial diversity. This may be due to an aberration in host response to microbial infection. This is evident by the increase in infectious and anastomotic complications in those with decreased diversity. With further investigation, this knowledge could lead to therapies aimed at improving the interaction between the microbiota and the host inflammatory signaling cascade to decrease perioperative complications.

\section{References}

1. Braga M, Ljungqvist O, Soeters P, Fearon K, Weimann A, Bozzetti F. ESPEN guidelines on parenteral nutrition: surgery. Clin Nutr. 2009;28:378-386.

2. Duro D, Kamin D, Duggan C. Overview of pediatric short bowel syndrome. J Pediatr Gastroenterol Nutr. 2008;47(suppl 1):S33-S36.

3. Spencer AU, Neaga A, West B, et al. Pediatric short bowel syndrome: redefining predictors of success. Ann Surg. 2005;242:403-409, discussion 409-412.

4. Gogos CA, Kalfarentzos F. Total parenteral nutrition and immune system activity: a review. Nutrition. 1995;11:339-344.

5. Perioperative total parenteral nutrition in surgical patients. The Veterans Affairs Total Parenteral Nutrition Cooperative Study Group. $N$ Engl J Med. 1991;325:525-532.

6. Minard G, Kudsk KA. Effect of route of feeding on the incidence of septic complications in critically ill patients. Semin Respir Infect. 1994;9:228-231.

7. Gramlich L, Kichian K, Pinilla J, Rodych NJ, Dhaliwal R, Heyland DK. Does enteral nutrition compared to parenteral nutrition result in better outcomes in critically ill adult patients? A systematic review of the literature. Nutrition. 2004;20:843-848.

8. Sigalet DL, Mackenzie SL, Hameed SM. Enteral nutrition and mucosal immunity: implications for feeding strategies in surgery and trauma. Can J Surg. 2004;47:109-116.

9. Li J, Kudsk KA, Gocinski B, Dent D, Glezer J, Langekamp-Henken B. Effect of parenteral and enteral nutrition on gut-associated lymphoid tissue. J Trauma. 1995;39:44-51.

10. Feng Y, McDunn JE, Teitelbaum DH. Decreased phospho-Akt signaling in a mouse model of total parenteral nutrition: a potential mechanism for the development of intestinal mucosal atrophy. Am J Physiol Gastrointest Liver Physiol. 2010;298:G833-G841.

11. Sun $\mathrm{X}$, Yang $\mathrm{H}$, Nose $\mathrm{K}$, et al. Decline in intestinal mucosal IL-10 expression and decreased intestinal barrier function in a mouse model of total parenteral nutrition. Am J Physiol Gastrointest Liver Physiol. 2008;294:G139-G147.

12. Yang H, Teitelbaum DH. Intraepithelial lymphocyte-derived interferongamma evokes enterocyte apoptosis with parenteral nutrition in mice. Am J Physiol Gastrointest Liver Physiol. 2003;284:G629-G637.

13. Feng Y, Sun X, Yang H, Teitelbaum D. Dissociation of E-cadherin and beta-catenin in a mouse model of total parenteral nutrition: a mechanism for the loss of epithelial cell proliferation and villus atrophy. J Physiol (London). 2009;587:641-654.

14. Fukatsu K, Kudsk KA. Nutrition and gut immunity. Surg Clin North Am. 2011;91:755-770.

15. Jonker MA, Hermsen JL, Sano Y, Heneghan AF, Lan J, Kudsk KA. Small intestine mucosal immune system response to injury and the impact of parenteral nutrition. Surgery. 2012;151:278-286.

16. Fukatsu K, Kudsk KA, Zarzaur BL, Wu Y, Hanna MK, DeWitt RC. TPN decreases IL-4 and IL-10 mRNA expression in lipopolysaccharide stimulated intestinal lamina propria cells but glutamine supplementation preserves the expression. Shock. 2001;15:318-322.

17. Yang H, Feng Y, Sun X, Teitelbaum DH. Enteral versus parenteral nutrition: effect on intestinal barrier function. Ann $N$ Y Acad Sci. 2009;1165:338-346.

18. Sun X, Yang H, Nose K, et al. Decline in intestinal mucosal IL-10 expression and decreased intestinal barrier function in a mouse model of total parenteral nutrition. Am J Physiol Gastrointest Liver Physiol. 2008;294:G139-G147.

19. Yang H, Finaly R, Teitelbaum DH. Alteration in epithelial permeability and ion transport in a mouse model of total parenteral nutrition. Crit Care Med. 2003;31:1118-1125. 
20. Kudsk KA, Croce MA, Fabian TC, et al. Enteral versus parenteral feeding: effects on septic morbidity after blunt and penetrating abdominal trauma. Ann Surg. 1992;215:503-511, discussion 511-513.

21. Kiristioglu I, Teitelbaum DH. Alteration of the intestinal intraepithelial lymphocytes during total parenteral nutrition. J Surg Res. 1998;79:91-96.

22. Kiristioglu I, Antony P, Fan YY, et al. Total parenteral nutrition-associated changes in mouse intestinal intraepithelial lymphocytes. Digest Dis Sci. 2002;47:1147-1157.

23. Morowitz MJ, Poroyko V, Caplan M, Alverdy J, Liu DC. Redefining the role of intestinal microbes in the pathogenesis of necrotizing enterocolitis. Pediatrics. 2010;125:777-785.

24. Maslowski KM, Mackay CR. Diet, gut microbiota and immune responses. Nat Immunol. 2011;12:5-9.

25. Miyasaka EA, Erb-Downward JR, Falkowski NR, Gillilland M, Huffnagle GB, Teitelbaum DH. Total parenteral nutrition (TPN) in a mouse model leads to major population shifts in the intestinal microbiome. Gastroenterology. 2011;140:S103.

26. Buchman AL, Moukarzel AA, Bhuta S, et al. Parenteral nutrition is associated with intestinal morphologic and functional changes in humans. JPEN J Parenter Enteral Nutr. 1995;19:453-460.

27. Reynolds JV, Kanwar S, Welsh FK, et al. 1997 Harry M. Vars Research Award. Does the route of feeding modify gut barrier function and clinical outcome in patients after major upper gastrointestinal surgery? JPEN $J$ Parenter Enteral Nutr. 1997;21:196-201.

28. Santos AA, Rodrick ML, Jacobs DO, et al. Does the route of feeding modify the inflammatory response? [see comments]. Ann Surg. 1994;220:155163.

29. Buchman A, Mestecky J, Moukarzel A, Ament M. Intestinal immune function is unaffected by parenteral nutrition in man. J Am Coll Nutr. 1995; 14:656-661.

30. Sedman PC, MacFie J, Palmer MD, Mitchell CJ, Sagar PM. Preoperative total parenteral nutrition is not associated with mucosal atrophy or bacterial translocation in humans [see comments]. Br J Surg. 1995;82:1663-1667.

31. De Filippo C, Cavalieri D, Di Paola M, et al. Impact of diet in shaping gut microbiota revealed by a comparative study in children from Europe and rural Africa. Proc Natl Acad Sci U S A. 2010;107:14691-14696.
32. Carlisle EM, Morowitz MJ. Pediatric surgery and the human microbiome. J Pediatr Surg. 2011;46:577-584.

33. Tilg H, Kaser A. Gut microbiome, obesity, and metabolic dysfunction. $J$ Clin Invest. 2011;121:2126-2132.

34. Willyard C. Microbiome gut reaction. Nature. 2011;479:S5-S7.

35. Costello EK, Stagaman K, Dethlefsen L, Bohannan BJ, Relman DA. The application of ecological theory toward an understanding of the human microbiome. Science. 2012;336:1255-1262.

36. Dowd SE, Callaway TR, Wolcott RD, et al. Evaluation of the bacterial diversity in the feces of cattle using $16 \mathrm{~S}$ rDNA bacterial tag-encoded FLX amplicon pyrosequencing (bTEFAP). BMC Microbiol. 2008;8:125.

37. Bailey MT, Dowd SE, Parry NM, Galley JD, Schauer DB, Lyte M. Stressor exposure disrupts commensal microbial populations in the intestines and leads to increased colonization by Citrobacter rodentium. Infect Immun. 2010;78:1509-1519.

38. Schloss PD, Westcott SL, Ryabin T, et al. Introducing mothur: opensource, platform-independent, community-supported software for describing and comparing microbial communities. Appl Environ Microbiol. 2009; 75:7537-7541.

39. Turnbaugh PJ, Ley RE, Hamady M, Fraser-Liggett CM, Knight R, Gordon JI. The human microbiome project. Nature. 2007;449:804-810.

40. Martin R, Nauta AJ, Ben Amor K, Knippels LM, Knol J, Garssen J. Early life: gut microbiota and immune development in infancy. Benef Microbes. 2010;1:367-382.

41. Penders J, Thijs C, Vink C, et al. Factors influencing the composition of the intestinal microbiota in early infancy. Pediatrics. 2006;118:511-521.

42. Weimann A, Braga M, Harsanyi L, et al. ESPEN guidelines on enteral nutrition: surgery including organ transplantation. Clin Nutr. 2006;25: 224-244.

43. Ley RE, Lozupone CA, Hamady M, Knight R, Gordon JI. Worlds within worlds: evolution of the vertebrate gut microbiota. Nat Rev Microbiol. 2008;6:776-788.

44. Adlerberth I, Wold AE. Establishment of the gut microbiota in Western infants. Acta Paediatr. 2009;98:229-238.

45. Guarner F, Malagelada JR. Gut flora in health and disease. Lancet. 2003;361:512-519. 